\title{
An alternative tourism model for sustainable development in Los Cabos, Baja California Sur, Mexico
}

\author{
O. Arizpe \& A. Gámez \\ Autonomous University of Southern Baja California, USA
}

\begin{abstract}
Baja California Sur (BCS) is the largest coastal state in Mexico and helps shape the Gulf of California. This northwestern region has a historical, cultural, and ecologic relevance that has recently been reassessed by the growing importance of tourism-related activities. Among them, eco-tourism has been acknowledged to have comparative advantage as a source of economic, environmental and social welfare, provided a process of planning, evaluation, control, and continuous adjustments is put in place. Yet as in the rest of the state territory the municipality of Los Cabos, BCS, Mexico, the most important tourist destination, has inadequate development plans. In the context of a high population and tourist pressure, the area has become extremely vulnerable. In order to counterbalance this trend and generate tools for decision makers, we characterized environmental, social and economic components in the Los Cabos municipality, emphasizing the tourism sector; public participation was included through community and government level workshops. A diagnosis was concluded, which included models and maps of economic aptitude or capacity for each micro region. As proven by our analysis, sustainable tourism could be a means for using natural and social resources in a profitable way. Decision makers and the community of Los Cabos will, nonetheless, face important challenges to strengthen the type of economic activities sustainable tourism involve versus the trend to traditional mass tourism, to secure public access to coasts and beaches, to protect landscape quality and, in general, to manage growth in the region.

Keywords: alternative tourism model, sustainable development, Los Cabos, Mexico.
\end{abstract}




\section{Introduction}

Mexico is one of the five most mega diverse countries in the world and is placed among the ten top tourist destinations in the planet. The Los Cabos region, in Baja California Sur, has a natural disposition towards tourism. The landscape is shaped by a mixture of mountains, desert and beaches; the diverse terrestrial and marine flora and fauna provide with a distinctive attraction; the Gulf of California, which bathes the state's oriental side, is deemed as the biggest aquarium of the world; and it all mixes to make Los Cabos an appealing site for visitors.

The municipality of Los Cabos, the southernmost portion of the Baja California Sur state, has become one of the fastest growing tourist destinations in Mexico. It has reached population growth rates in an average of $10 \%$ during the last decade. Tourism has mainly developed along the San José del Cabo-Cabo San Lucas corridor, and has rested on a high income tourism market that feeds on visitors from the United States and which relies on high level infrastructure to attend to this sector (Urciaga [1], SEMARNAT [2]).

An example that illustrates the importance of tourism for the economy of Los Cabos is the outstanding number of visitors it receives in comparison to the rest of the state. Beginning at the end of the 1980s and continuing through 2008, Los Cabos received 70 per cent of the 1.7 million tourists that visited Baja California Sur (Gobierno de BCS [3]). In contrast to other municipalities, its affluence is principally composed of foreign tourism. These visitors are generally 80 percent of the total visitors to the locale and reached 91 percent in 2008, which shows a long lasting trend in the region (CEI [4]). Similar to other parts of the world, growth is focused on traditional tourism, sometimes called high density tourism. The importance of growth in this activity, both at the local and international levels, has also produced its diversification. At the world level this has created an increasingly intense current in the development of tourist poles, fundamentally characterized by the search for unconventional forms in places where the human impact is minimal, and that allow for the use of conservation measures or intelligent uses of the ecosystem. This has given rise to what is called alternative tourism. Wearing and Neil [5] define this type of tourism as a series of modalities with objectives that follow from natural, social and communitarian values and that permit the enjoyment of positive and share experiences for both the hosts and the visitors. This form of tourism includes ecotourism (recreational activities associated with appreciation and encounter of nature), adventure tourism (recreational activities and sports associated with the challenges imposed by nature), and rural tourism (activities that share and interact with rural communities in all of their daily life, including social, cultural and productive endeavors).

In the Los Cabos region, particularly in the last decade, it has been repeatedly stated in different forums, that the tourism development model that is traditionally followed in the municipality and is based on sun, beaches, and high density, cannot continue over the long run and requires the study of more sustainable alternatives for development (Angeles and Gámez [6], Gámez [7]). Focus on the concentration of tourist activities and the resulting social and 
environmental effects was the motive for the signing of an agreement in February, 2007, between the city of Los Cabos and the Autonomous University of Baja California Sur (UABCS) calling for the formulation and adoption of a Municipal Ecology Ordinance. Built on sectorally based workshops and surveys of the public and key actors, it was noted that the socioeconomic development of the municipality should be grounded in harmony with the natural environment, and should promote scientific knowledge about the integration of social, economic and natural process in order to achieve a higher quality of life for everyone (Arizpe et al. [8]).

\section{Development of the model}

The proposed model of tourism generated in that study (Arizpe et al. [8]) included the following indices, indicators, and weights:

$$
\mathrm{IT}=\mathrm{ANAT}+\mathrm{ACULT}+\mathrm{SERV}+\mathrm{INFRA}
$$

The Tourism index (IT) is made up of the indexes for natural attractions (ANAT), cultural attractions (ACULT), services (SERV) and infrastructure (INFRA). In order to implement weights, considerations were given to the results of the survey of the tourism sector, consultations and workshops with public participation, Delphi surveys of experts, and the existing research on the subject (Arizpe et al. [8]).

For traditional sun and beach tourism, the greatest weight was given to infrastructure, followed by services. Minor importance was given to natural attractions and the smallest weight was placed on cultural attractions.

$$
\text { IT }=\text { ANAT }(0.25)+\operatorname{ACULT}(0.15)+\operatorname{SERV}(0.3)+\operatorname{INFRA}(0.3)
$$

Given the limits of traditional sun and beach tourism, a model measuring the aptitude for alternative tourism was developed using the same methodology. As will be observed, the model's components are the same but the weights are very different from the traditional tourism model. The most important value was for natural attractions (ANAT), followed by cultural attractions (ACULT), services (SERV) and infrastructure (INFRA). The following equation shows the standardized values for the alternative tourism model, and the break down of the components and values for each of the indexes:

$$
\text { ITALT }=\text { ANAT (4) }+ \text { ACULT (2) }+ \text { SERV (1) + INFRA (1) }
$$

INDEX OF NATURAL ATTRACTIONS (ANAT) $=$ ANP $(0.11)+\mathrm{AV}(0.11)+$

$$
\mathrm{AF}(0.11)+\mathrm{PL}(0.45)+\mathrm{LAG} / \mathrm{BA}(0.22)
$$

$\mathrm{ANP}=$ Presence/absence of natural protected areas

$\mathrm{AV}=$ Presence/absence of natural vegetation attractions

$\mathrm{AF}=$ Presence/absence of wild animal attractions

$\mathrm{PL}=$ Number of beaches 
$\mathrm{LAG} / \mathrm{BA}=$ Presence/absence of Lagoons and bays INDEX OF CULTURAL ATTRACTIONS (ACUL) $=$ ARQ $(0.33)+$ HIST

$$
(0.33)+\text { PAL (0.33) }
$$

$\mathrm{ARQ}=$ Number of archaeological sites

HIST $=$ Number of historical sites

$\mathrm{PAL}=$ Number of paleontological sites

INDEX OF TOURISM SERVICES $($ SERV) $=\operatorname{SCOST}(0.665)+\operatorname{STERR}$

COASTAL TOURISM SERVICES $($ SCOST $)=$ PORT + NAUT + BU + PDEP

$$
+ \text { FMAR + ZOSU }
$$

PORT $=$ Number of port services

NAUT $=$ Number of nautical services

$\mathrm{BU}=$ Number of diving services

PDEP $=$ Number of sport fishing services

FMAR $=$ Number of marine life viewing sites

$\mathrm{ZOSU}=$ Number of surfing sites

LAND-BASED TOURISM SERVICES = ACAMP + TALT

ACAMP $=$ Number of camping services

TALT $=$ Number of alternative tourism services

INDEX OF TOURISM INFRASTRUCTURE (INFRA) $=\operatorname{ICOM}(0.4)+\operatorname{IHOT}$ (0.6)

INDEX OF COMMUNICATION ROUTES $(\operatorname{ICOM})=\operatorname{PAV}(0.3)+\operatorname{TERR}(0.1)$

$$
+\operatorname{AINT}(0.3)+\operatorname{ANAC}(0.2)+\operatorname{APIST}(0.1)
$$

$\mathrm{PAV}=$ Kilometers of paved highways

TERR $=$ Kilometers of dirt roads

AINT $=$ Presence/absence of international airports

$\mathrm{ANAC}=$ Presence/absence of national airport

APIST $=$ Presence/absence of landing strips

INDEX OF LODGING INFRASTRUCTURE $($ IHOT $)=$ CHOT

$$
\mathrm{CHOT}=\text { Number of hotel rooms }
$$




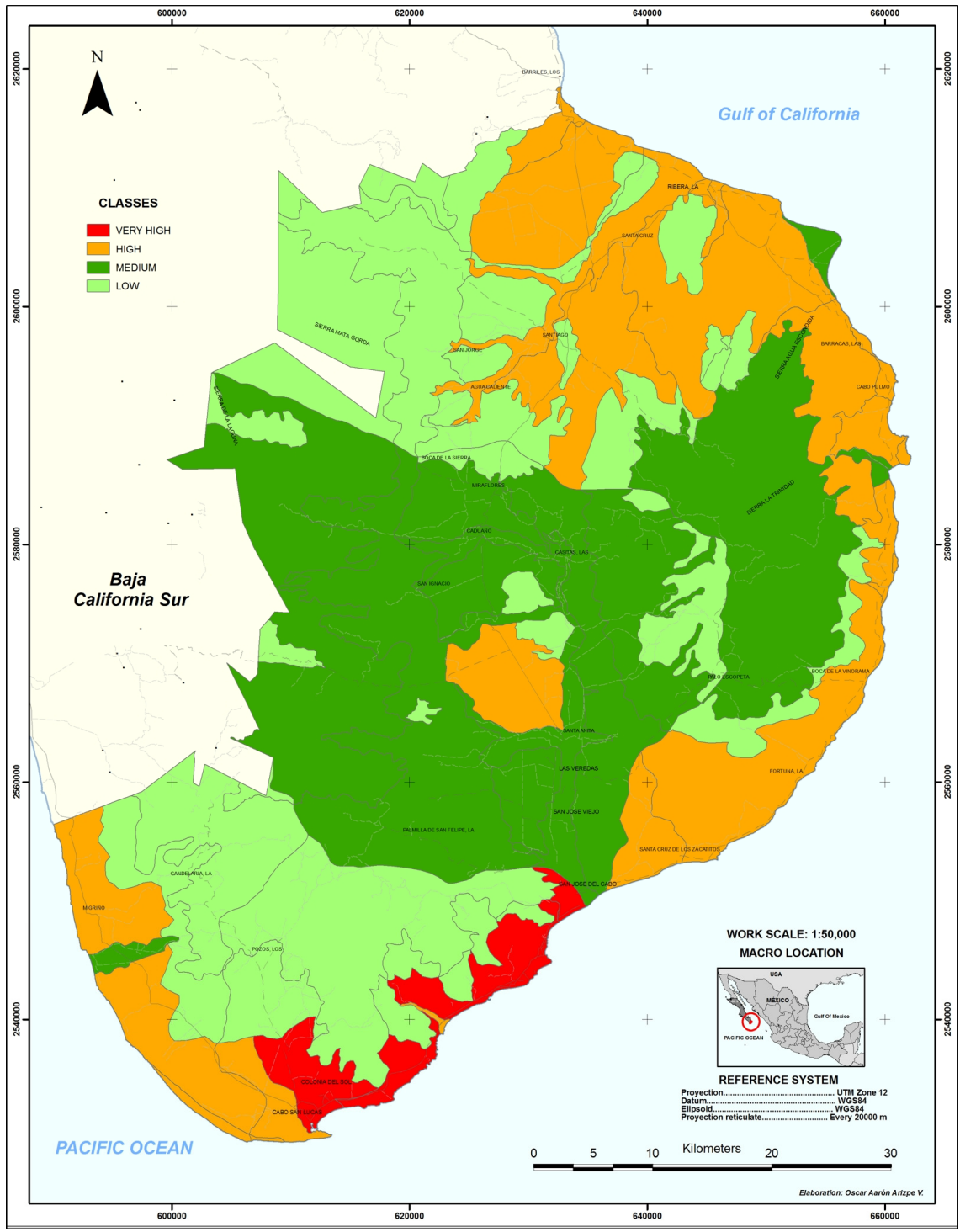

Figure 1: Extent of traditional tourism in the Municipality of Los Cabos, Mexico.

\section{Results}

\subsection{Traditional tourism}

With this model we estimated the aptitude of the high density tourism sector for Los Cabos, as shown in Figure 1. The tourism corridor Cabo San Lucas-San José 
del Cabo has a "very high" aptitude. The coastal zone has a "high" aptitude and some of the Environmental Units have a "medium" aptitude. The "very high" aptitude zones include only 3.1 percent, while the "high" aptitude includes 25.7 percent of the surface of the municipality. The zones of "medium" aptitude for tourism are located in the environmental units of the Sierra La Trinidad mountains in the central part of the municipality. The northern parts of the municipality, consisting of the Sierra La Laguna mountains, the environs of Sierra La Laguna, and the southwest away from the coast, have a "low" aptitude. In addition, we observed that 28.8 percent of the surface of the municipality of Los Cabos is capable of high density tourism.

\subsection{Alternative tourism}

Our results show that alternative tourism generates very different outcomes in the evaluation of each micro-region's aptitude. The regions with the greatest aptitude or capacity are situated in the north of the municipality. First, in the East Cape region and principally in the coastal zone of the Cabo Pulmo National Park, also in the regions of the channel of the San Dionisio-La Zorra arroyo, located in the northeast of the municipality, and finally, the Biosphere Reserve of the Sierra La Laguna and its southern reaches, which were not important areas for traditional tourism.

This strategy and methodology can be used to characterize and map all of the micro-regions in areas of interest in terms of their suitability for each type of tourism. The key is to follow the detailed procedures for evaluating and weighting precisely the components, indicators, and indexes. This methodology can be used to direct the planning and development of sustainable tourist activities with objective criteria and a formal quantitative technique.

\section{Final considerations}

Faced with the exponential growth of the tourism sector and related real estate development in Baja California Sur and specifically in the municipality of Los Cabos, the challenge arose to situate tourist centers in a manner that would secure a sustainable development. In this way, one understands those places with an orderly growth record, where development planning points toward the conservation of success over the long run and where the population experiences growth in its standard of living. Unfortunately, this has not occurred in any of the tourist centers of the nation, nor in those of the state, which puts at risk the continuation of growth in tourism in places that are vulnerable and lack the ability to maintain the quality of the services and natural resources that visitors expect.

Considering the obvious demonstrations of visual, economic, and social disequilibria that impose a heavy weight on governments responsible for providing services and public assistance, urban planning errors continue to be committed. These errors permit over construction, beaches are allowed to be 


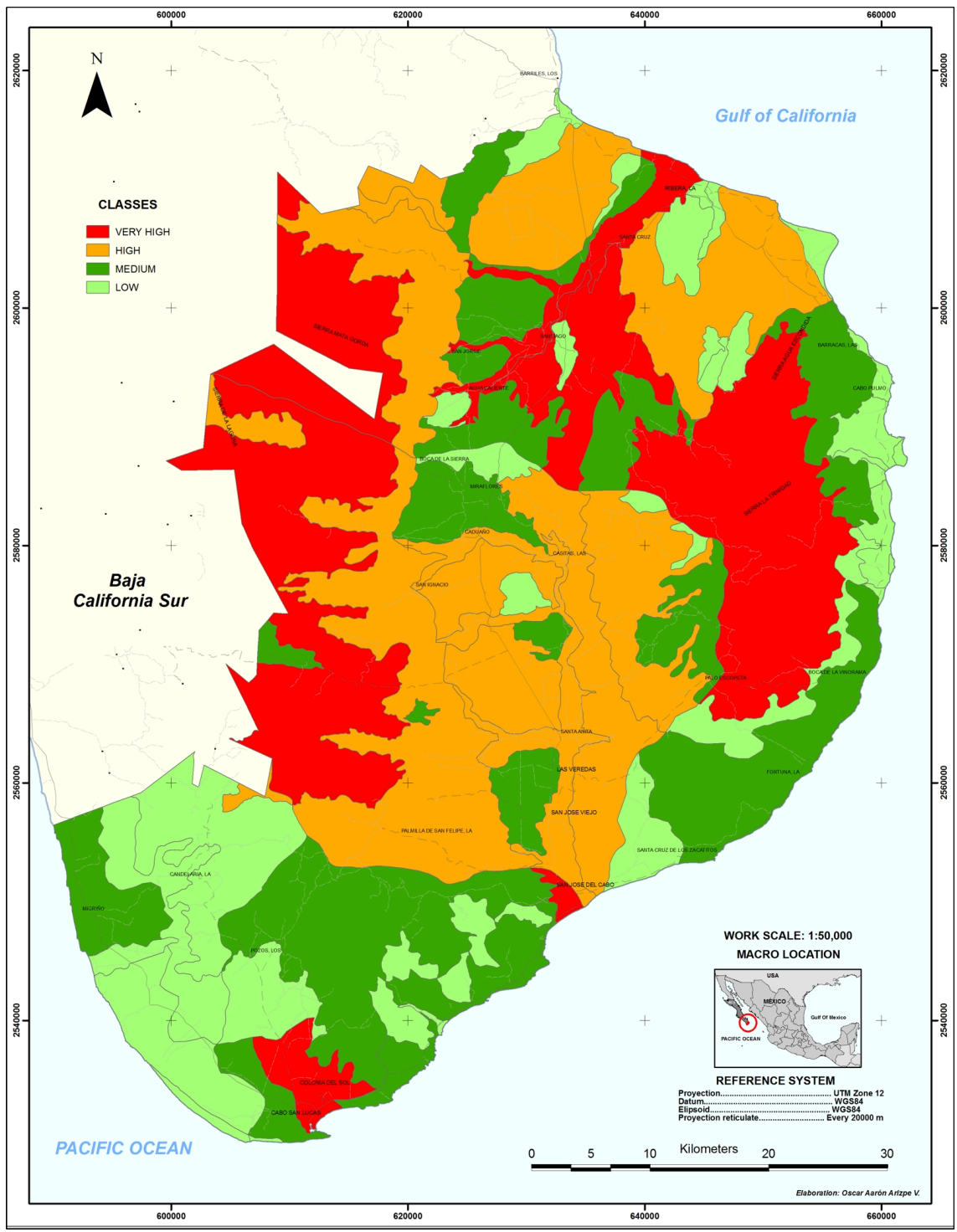

Figure 2: Suitability of alternative tourism in the municipality of Los Cabos, Baja California Sur.

become polluted while ecosystems that are emblematic are destroyed, towns become saturated with traffic, that overcrowding and the appearance of zones of misery continue to undermine the urban image, creating not only disincentives for tourists but also a deep sense of negative well-being in the resident population. 
It is an unavoidable challenge for society, government, and the private sector to change this situation, so that the type and rhythm of tourism growth will not remain indefinitely. Therefore, it is a social responsibility to anticipate the future of the region with an effective form of planning. In this sense it is necessary to promote models in which not all the region is susceptible to the same type of tourism activity or with the same intensity. The development and application of the idea of the present and future suitability of tourism in the different locations of the municipality (and other regions of the state as well) will permit it to utilize the elements of anticipation, planning, and adaptation of the tourism sector to the swings in the international economy and the carrying capacity of the ecosystems.

\section{References}

[1] Urciaga García, J., Turismo alternativo. Una estrategia de desarrollo del espacio rural para Baja California Sur, Prospectiva Económica, 3 (5), Juliodiciembre, pp. 177-197, 2004.

[2] SEMARNAT. Secretaría de Medio Ambiente y Recursos Naturales, Indicadores básicos del desempeño ambiental de México: 2005, PNUDSEMARNAT: México, 2005.

[3] Gobierno del Estado de Baja California Sur, IV Informe de Gobierno del Ing. Narciso Agúndez Montaño. Anexo Gráfico y Estadístico, Gobierno del Estado de BCS: La Paz, BCS, 2009.

[4] CEI. Centro Estatal de Información, Cuaderno de Datos Básicos 2006, Gobierno del Estado de Baja California Sur, Secretaría de Promoción y Desarrollo Económico: La Paz, BCS, 2006.

[5] Wearing, S. Neil, J., Ecoturismo. Impacto, tendencias y posibilidades, Síntesis: Madrid, 2000.

[6] Angeles, M. \& Gámez, A., Globalización y Desarrollo Regional. El Caso del Sector Turismo en Baja California Sur. Globalización y regionalismo: economía y sustentabilidad, eds. A. Ivanova \& A. Guillén, Porrúa: México, DF, pp. 463-484, 2008.

[7] Gámez, A. E., El crecimiento del sector turismo en Baja California Sur. Del saqueo a la conservación. Historia ambiental contemporánea de Baja California sur, 1940-2003, eds. M. Cariño \& M. Monteforte, UABCSSEMARNAT-INE-CONACYT: La Paz, BCS, pp. 365-388, 2008.

[8] Arizpe, O., Fermán, J., Rivera, R., Ramírez. J. \& Rodríguez, R., Evaluation and Land Use Planning Process of a High Population Growth Rate Municipality: Los Cabos, Mexico, WIT Transactions on Ecology and Environment $V$, pp. 87-95, 2008. 